\title{
Long Non-Coding RNA H19 Regulates Human Lens Epithelial Cells Function
}

\author{
Xin Liu, ${ }^{a, c, d} \quad$ Chang Liub,d,e Kun Shan ${ }^{b, d}$ Shujie Zhang ${ }^{b, c, d} \quad$ Yi Lu $u^{a, c, d}$ \\ Biao Yan ${ }^{b, c, d}$ Yi Luo ${ }^{a, c, d}$
}

aDepartment of Ophthalmology, Eye and ENT Hospital of Fudan University, Shanghai, ${ }^{\circ}$ Research Center, Eye and ENT Hospital of Fudan University, Shanghai, 'Key NHC Key Laboratory of Myopia (Fudan University); Laboratory of Myopia, Chinese Academy of Medical Sciences, Shanghai ${ }^{~}$ Shanghai Key Laboratory of Visual Impairment and Restoration, Fudan University, Shanghai, eThe Fourth School of Clinical Medicine, Nanjing Medical University, Nanjing, China

\section{Key Words}

Long non-coding RNA $\bullet$ Nuclear age-related cataract $\bullet$ miRNA $\bullet$ CRYAA

\begin{abstract}
Background/Aims: Age-related cataract (ARC) remains the leading cause of visual impairment among the elderly population. Long non-coding RNAs (IncRNAs) have emerged as potential regulators in many ocular diseases. However, the role of IncRNAs in nuclear ARC, a subtype of ARC, requires further elucidation. Methods: LncRNA sequencing was performed to identify differentially expressed IncRNAs between the capsules of transparent and nuclear ARC lenses. Expression validation was confirmed by qRT-PCR. MTT assay, Calcein-AM and propidium iodide double staining, Rhodamine 123 and Hoechst double staining, EdU and transwell assay were used to determine the role of $\mathrm{H} 19$ or miR-675 in the viability, apoptosis, proliferation and migration of primary cultured human lens epithelial cells (HLECs). Bioinformatics and luciferase reporter assays were used to identify the binding target of miR-675. Results: Sixtythree IncRNAs are differentially expressed between the capsules of transparent and nuclear ARC lenses. One top abundantly expressed IncRNA, H19, is significantly up-regulated in the nuclear ARC lens capsules and positively associated with nuclear ARC grade. H19 knockdown accelerates apoptosis development and reduces the proliferation and migration of HLECs upon oxidative stress. $\mathrm{H} 19$ is the precursor of miR-675, and a reduction of $\mathrm{H} 19$ inhibits miR675 expression. miR-675 regulates CRYAA expression by targeting the binding site within the $3^{\prime}$ UTR. Moreover, miR-675 increases the proliferation and migration while decreasing the apoptosis of HLECs upon oxidative stress. Conclusion: $\mathrm{H} 19$ regulates HLECs function through miR-675-mediated CRYAA expression. This finding would provide a novel insight into the pathogenesis of nuclear ARC.

\begin{tabular}{ll}
\hline Yi Luo & Department of Ophthalmology, Eye and ENT Hospital, Fudan University \\
and Biao Yan & 83 Fenyang Road, Shanghai 200031 (China) \\
& E-Mail yeeluo1106@163.com; biao.yan@fdeent.org
\end{tabular}




\section{Introduction}

Age-related cataract (ARC) remains the leading cause of visual impairment and blindness among the elderly population [1]. Surgical intervention is still the effective therapy for cataract. However, the demographic characteristics and high cost of surgery poses a great economic burden for society, especially in developing countries [2]. In addition, irreversible vision-threatening surgery-associated complications may also occur [3]. Thus, alternative pharmacological therapy is still required to prevent or delay senile cataract development. ARC is divided into several subtypes, including cortical, nuclear, and posterior subcapsular cataracts [4]. The distinct clinical features are associated with different aetiologies or susceptibilities of different lens regions [5]. Of them, nuclear cataract ranks the highest in number of incidences and experiences the most rapid deterioration in the patient's vision after progression [6-8] . However, the precise mechanism of nuclear ARC requires further clarification.

Epigenetic modifications are post-transcriptional, hereditable and reversible events, including DNA methylation, histone modification, genomic imprinting, chromatin remodelling and non-coding RNA regulation [9]. Critical enzymes involved in DNA methylation, such as DNMT1 and MeCP2, have been identified in human lens epithelial cells (HLECs) $[10,11]$. Epigenetic regulatory processes, including DNA methylation of CRYAA [9, 10, 12-14], histone acetylation of SOD1 [15] and long non-coding RNA (lncRNA)-MIAT and KCNQ10T1 [16, 17], have been implicated in the pathological cataractogenesis.

LncRNAs are identified as a class of transcripts greater than 200 nucleotides in length with limited protein-coding potential $[18,19]$. Aberrant expressions of lncRNAs have emerged as key events in several biological processes $[18,20]$. Our previous study reveals that lncRNAMIAT is up-regulated in cataractous lenses. MIAT acts as a ceRNA and forms a feedback loop with Akt and miR-675-5p to regulate the function of HLECs [16]. However, we did pay attention to the relationship between IncRNA expression and ARC subtypes, especially the most prevalent nuclear cataract type. In addition, compared to the lncRNA microarray, the newly emerging IncRNA sequencing technology provides a far more precise measurement of the entire transcriptome in a very high-throughput and quantitative manner $[20,21]$. Based on the above-mentioned reasons, we employed the IncRNA sequencing technique to identify nuclear ARC-related IncRNAs. We show that 63 lncRNAs are differentially expressed between transparent and nuclear ARC lenses, including 37 down-regulated lncRNAs and 26 up-regulated lncRNAs. Of them, H19 is the most up-regulated in nuclear ARC lens capsules. H19 knockdown could affect the apoptosis, proliferation and migration of HLECs, suggesting a potential role of $\mathrm{H} 19$ in nuclear ARC formation.

\section{Materials and Methods}

\section{Ethics statement}

This study was performed in accordance with the tenets of the Declaration of Helsinki for research involving human subjects. The institutional review board of the Eye and ENT Hospital of Fudan University approved the use of human lens samples from post-mortem eyes and cataract eyes during surgery. Written informed consents were obtained from the patients before surgery.

\section{Human lens epithelium samples}

Lens epithelium samples were collected from the post-mortem eyes ( 9 donors for IncRNA sequencing and 30 donors for qRT-PCR verification, donor age range of 50-62 years, free of ocular diseases) and nuclear ARC patients ( 9 patients for lncRNA sequencing and 120 patients for qRT-PCR verification, patient age range of 51-75 years, free of other ocular diseases). The type and severity of cataracts were determined according to the modified version of lens opacity classification system III (LOCSIII) [4]. Agreement in the assessment of cataract grading was noted by three experienced ophthalmologists, independently and simultaneously. Lenses from post-mortem eyes were obtained from the Eye Bank at the Eye and ENT Hospital of Fudan University within 8 hours after donor death. These samples with LOCSIII scores of NC1 to approximately NC2 were used as the control group. Lenses with a score of NC3 to approximately NC6 were selected as the nuclear ARC group. These lens epithelium samples were acquired by intact continuous curvilinear capsulorhexis (5-6 mm diameter) during cataract surgery for nuclear ARC patients by the same experienced surgeon (Yi Luo). An anterior epithelium sample of one lens did not contain sufficient RNA 


\section{Cellular Physiology Cell Physiol Biochem 2018;50:246-260

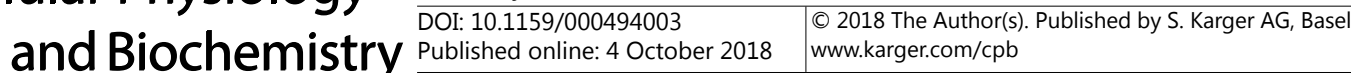

Liu et al.: H19 Regulates HLECs Function

for RNA sequencing and qRT-PCR analysis. Therefore, the anterior epithelium samples of three lenses (transparent or cataractous) were pooled together as a biological repeat to obtain enough RNAs.

\section{RNA extraction and IncRNA sequencing}

All epithelium samples were cooled with liquid nitrogen and homogenised in TRIzol reagent (Invitrogen, Carlsbad, CA, USA). Total RNAs were isolated using the RNeasy Mini Kit (Qiagen, Valencia, CA) according to the manufacturer's instructions. LncRNA sequencing procedures were performed by the Beijing Genomics Institute (BGI) in China. In brief, $1 \mu \mathrm{g}$ total RNA was used for library construction, including rRNA depletion, RNA fragmentation, first strand cDNA synthesis, second strand cDNA synthesis, ends repair, A-Tailing, adapter ligation, Uracil-N-Glycosylase digestion and polymerase chain reaction (PCR) amplification. After the library validation, the qualified libraries were amplified on cBot to generate the cluster on the flowcell (TruSeq PE Cluster Kit V3-cBotHS, Illumina, USA). In addition, the amplified flowcell was pairedend sequenced on the HiSeq 2000 System (TruSeq SBS KIT-HS V3, Illumina, USA) platform.

\section{Quantitative real-time reverse transcription-polymerase chain} reaction ( $q R T-P C R)$

One $\mu \mathrm{g}$ of total RNA was reversely transcribed with the PrimeScript $^{\mathrm{TM}}$ RT Reagent Kit (Takara Bio, Japan) in accordance with the manufacturer's protocol. LncRNAs were reversely transcribed using oligo (dT) and random primers; mRNAs were reversely transcribed using oligo (dT) primers; and microRNAs were reversely transcribed with RT primers. LncRNA and mRNA expressions were detected using a SYBR Green detection kit (SYBR Premix Ex Taq; Takara, Japan). GAPDH or U6 was detected as the internal control. The primers used in qRT-PCRs are listed in Table 1. The qRT-PCR reactions were performed using a ViiA 7 RealTime PCR System (Life Technologies, USA). Relative changes in gene expression were determined by calculating $2^{-\Delta \Delta C \mathrm{~T}}$ with ViiA 7 software (Life Technologies, USA).

\section{Primary cell culture}

Twenty fragments of anterior capsule from patients of a mean age of $55.5 \pm 3.3$ years were obtained by capsulotomy during cataract surgery. Each capsule was placed in a $1.5-\mathrm{ml}$ microcentrifuge tube with growth medium containing Dulbecco's Modified Eagle Medium (DMEM, Gibco, USA) with 20\% fetal bovine serum (FBS, Gibco, USA). Antibiotic agents were not added. The collected capsule was cut into small pieces (approximately $2 \mathrm{~mm}$ in diameter) and transferred to a 35-mm culture Petri dish. A sufficient amount of growth medium was added to the culture dish to just cover the capsule pieces. After 1 day, more growth medium was added into the culture to reach the total volume of $1 \mathrm{ml}$. After 7 days, an outgrowth of HLECs was observed around the edge of the capsule pieces. To obtain the maximum number of cells, the cell culture was treated with trypsin-EDTA (Gibco, USA) for 5 min to dissociate the cells from the bottom of the culture dish. After the addition of fresh medium, the culture dish was incubated for 1 additional week with medium changes every other day. By this point, the proliferating cells covered the entire dish and were used for the following experiments.

Unless otherwise indicated, these cells were grown to $70-80 \%$ confluence and then serum-starved overnight prior to treatment.

\section{Cell transfection}

H19 siRNA (GACACCAUCGGAACAGCAG)/miR-675 inhibitor/miR-675 mimics and their negative controls were purchased from RiboBio Co. (China). They were transfected using Lipofectamine 2000 (Invitrogen, USA) according to the manufacturer's protocol. A total of $1 \times 10^{5}$ cells in $1 \mathrm{ml}$ of medium were
Table 1. Primer sequence for gene amplification

\begin{tabular}{|c|c|c|}
\hline Gene ID & & Primer \\
\hline \multirow{2}{*}{ n344497 } & Forward & TCCCATAGAACCACGGAGAC \\
\hline & Reverse & AGCACAGGGCTCTAACAGGA \\
\hline \multirow{2}{*}{ n364478 } & Forward & GGGAAAGCCACATAATGGAA \\
\hline & Reverse & CCTTAGGCTGAGCACCTCTG \\
\hline \multirow{2}{*}{ n411089 } & Forward & GTGGCCTCTGCAGCATAAAT \\
\hline & Reverse & CAGGCAGGAGAAGCTGTGTT \\
\hline \multirow{2}{*}{ n377732 } & Forward & TCTCTCAGGTTTGGGGTCTG \\
\hline & Reverse & CCAGAGCTTCCTGAGGTCAC \\
\hline \multirow{2}{*}{ H19 } & Forward & CGGACACAAAACCCTCTAGC \\
\hline & Reverse & GCTGTTCCGATGGTGTCTTT \\
\hline \multirow{2}{*}{ n373829 } & Forward & CGAAGGGAATGATCTGGCTA \\
\hline & Reverse & GCCAGCACCCTCATTTAGAG \\
\hline \multirow{2}{*}{ n1867 } & Forward & TTGAAAGCCCAGCCCATTTC \\
\hline & Reverse & AACTCCGTGTCCCTTGTGAT \\
\hline \multirow{2}{*}{ n373699 } & Forward & TCCACGGGTCACTTCAAGAT \\
\hline & Reverse & GGCTGGTGATTGGAGGTTTA \\
\hline \multirow{2}{*}{ n377732 } & Forward & CAGCCGAAGGAACTTCTCAC \\
\hline & Reverse & GTGGCCTCTGCAGCATAAAT \\
\hline \multirow{2}{*}{ n346362 } & Forward & CAGGCAGGAGAAGCTGTGTT \\
\hline & Reverse & AGTCATCCGCACATCCAGTT \\
\hline \multirow{2}{*}{ GAPDH } & Forward & GGCCTCCAAGGAGTAAGACC \\
\hline & Reverse & AGGGGAGATTCAGTGTGGTG \\
\hline \multirow{2}{*}{ IGF2 } & Forward & GTGGCATCGTTGAGGAGTG \\
\hline & Reverse & CACGTCCCTCTCGGACTTG \\
\hline \multirow{5}{*}{ miR-675-5p } & & GTCGTATCCAGTGCGTGTCGTG \\
\hline & RT & GAGTCGGCAATTGCACTGGA \\
\hline & & TACGACTGAGCT \\
\hline & Forward & GGGTGAGATGAAGCACTGT \\
\hline & Reverse & CAGTGCGTGTCGTGGAGT \\
\hline \multirow{3}{*}{ U6 } & RT & CGCTTCACGAATTTGCGTGTCAT \\
\hline & Forward & GCTTCGGCAGCACATATACTAAAAT \\
\hline & Reverse & CGCTTCACGAATTTGCGTGTCAT \\
\hline \multirow{2}{*}{ CRYAA } & Forward & CCTGCTGCCCTTCCTGTCGT \\
\hline & Reverse & TCCTGGCGCTCGTTGTGCT \\
\hline \multirow{2}{*}{ Twist1 } & Forward & GTCCGCAGTCTTACGAGGAG \\
\hline & Reverse & GCTTGAGGGTCTGAATCTTGCT \\
\hline \multirow{2}{*}{ RB1 } & Forward & TTGGATCACAGCGATACAAACTT \\
\hline & Reverse & AGCGCACGCCAATAAAGACAT \\
\hline \multirow{2}{*}{ СаMKII $\delta$} & Forward & AGGGCTTTCACTACTTGGTGT \\
\hline & Reverse & AGCCAAAGTCTGCCAATTTCA \\
\hline \multirow{2}{*}{ RUNX1 } & Forward & GAGCTGAGAAATGCTACCGC \\
\hline & Reverse & TGATGGCTCTGTGGTAGGTG \\
\hline \multirow{2}{*}{ p53 } & Forward & GAGGTTGGCTCTGACTGTACC \\
\hline & Reverse & TCCGTCCCAGTAGATTACCAC \\
\hline \multirow{2}{*}{ TGF- $\beta 1$} & Forward & GGCCAGATCCTGTCCAAGC \\
\hline & Reverse & GTGGGTTTCCACCATTAGCAC \\
\hline \multirow{2}{*}{ Smad3 } & Forward & ССATCTCCTACTACGAGCTGAA \\
\hline & Reverse & CACTGCTGCATTCCTGTTGAC \\
\hline
\end{tabular}




\section{Cellular Physiology Cell Physiol Biochem 2018;50:246-260 \begin{tabular}{ll|l} 
and Biochemistry & $\begin{array}{l}\text { DOI: 10.1159/000494003 } \\
\text { Published online: 4 October } 2018\end{array}$ & $\begin{array}{l}\text { (c) } 2018 \text { The Author(s). Published by S. Karger AG, Basel } \\
\text { www.karger.com/cpb }\end{array}$
\end{tabular}}

Liu et al.: H19 Regulates HLECs Function

seeded in 24-well plates. siRNA (50 nM), miR-675 inhibitor (100 nM), or miR-675 mimics (50 nM) was then gently introduced into the cells by mixing with the required amount of transfection reagent.

\section{MTT assay}

Cell viability was determined using 3-(4, 5-dimethylthiazal-2-yl)-2, 5-diphenyl-tetrazolium bromide (MTT) assay as previously described [22]. Briefly, SRA01/04 cells were plated onto 96-well plates at a density of $1 \times 10^{4}$ cells/well in $0.1 \mathrm{ml}$ of DMEM medium. After the transfection of siRNA-H19, miR-675 inhibitor, miR-675 mimic, or their negative controls for $48 \mathrm{~h}$, these cells were incubated with MTT at a final concentration of $0.5 \mathrm{mg} / \mathrm{ml}$ for $4 \mathrm{~h}$ at $37^{\circ} \mathrm{C}$. The formazan crystals were dissolved by adding $100 \mathrm{mM}$ DMSO after medium removal. Absorbance was measured using a microplate reader (Synergy 4 Hybrid Multi-Mode; BioTek Instruments, Canada).

Calcein-AM and propidium iodide double staining

Calcein-AM and propidium iodide (PI) double staining was used to distinguish live and dead cells. After the specific treatment, HLECs were washed twice with phosphate buffer saline (PBS), and then stained with PI $(10 \mu \mathrm{mol} / \mathrm{l}$; Molecular Probes, USA) for $30 \mathrm{~min}$. After three washings with PBS, these cells were stained with Calcein-AM solution (10 $\mu \mathrm{mol} / \mathrm{l}$; Molecular Probes, USA) for $30 \mathrm{~min}$. The live cells were observed using a fluorescence microscope (DMI 3000B; LEICA, Germany) at $490 \mathrm{~nm}$ excitation filter, while the dead cells were observed using a $545 \mathrm{~nm}$ excitation filter.

\section{Rhodamine 123 and Hoechst 33342 double staining}

Rhodamine 123 (Beyotime Biotechnology, China) staining was used to determine mitochondrial membrane potential $(\Delta \Psi \mathrm{m})$. As a cationic fluorescent indicator, Rhodamine 123 could selectively accumulate within mitochondria in a membrane potential-dependent manner. HLECs were cultured in 24-well plates. After the required treatment, HLECs were washed twice with PBS and then stained with $2 \mu \mathrm{M}$ Rhodamine 123 for $15 \mathrm{~min}$. After three washes with PBS, these cells were stained with Hoechst $33342(100 \mu \mathrm{g} / \mathrm{ml}$, Beyotime Biotechnology, China) for $10 \mathrm{~min}$ to visualise the nuclei. The excess staining was removed by rinsing with several changes of PBS. Images were taken using the fluorescence microscope (DMI 3000B; LEICA, Germany). Green Rhodamine 123 fluorescence reduction indicated the dissipated $\Delta \Psi \mathrm{m}$.

\section{EdU incorporation assay}

Cell proliferation was detected using a Cell-Light EdU Apollo 567 In Vitro Kit (RiboBio Co., China) according to the manufacturer's protocols. In brief, HLECs were plated in 96-well plates. After the required treatment, 5-Ethynyl-2'-deoxyuridine (EdU) was added into each well and incubated for $3 \mathrm{~h}$. After washing twice with PBS, the cells were fixed with $4 \%$ paraformaldehyde for $30 \mathrm{~min}$ at room temperature. Then, cells were incubated with Apollo staining reaction liquid for $30 \mathrm{~min}$ to detect the positive cells. The cells were counterstained with Hoechst 33342. Immunofluorescence was observed with a fluorescence microscope (DMI 3000B; LEICA, Germany).

\section{Transwell assay}

Cell migration was determined by the transwell assay. After the required treatment, $5 \times 10^{4}$ cells were transferred on the upper chamber of $8 \mu \mathrm{m}$ hanging inserts in the 24-well plates (Corning, USA) in a serumfree DMEM. A volume of $800 \mu \mathrm{l}$ of $10 \%$ FBS-containing DMEM was then added to the lower chamber. After $24 \mathrm{~h}$ incubation, the non-invaded cells were removed with cotton swabs. The invaded cells were fixed with 4\% paraformaldehyde for $15 \mathrm{~min}$ and stained with $0.1 \%$ Crystal Violet (Beyotime Biotechnology, China) for $30 \mathrm{~min}$ and photographed. Three different microscopic fields were counted, and the average number was calculated.

MicroRNA binding target prediction

Potential binding targets of miR-675 were predicted by using the Targetscan website (http://www. targetscan.org) as described previously in [23].

Dual luciferase assay

Full-length human CRYAA 3'-UTR was amplified by PCR using forward primer 5'-GCGGCTCGAGCCCTCGTCCTAAGCAGGCATT-3' (CRYAA-3'UTR-F) and reverse primer 5'-AATGCGGCCGCGCGCCCCTGATGGAGACAG-3' (CRYAA-3'UTR-R). The amplified 3'-UTR of CRYAA was cloned into the downstream of the luciferase gene in pmiR-RB-REPORT luciferase vector (RiboBio Co., China) to generate the pmiR-CRYAA-WT vector. The 3'-UTR without predicted miR-675-5p binding site was constructed to generate pmiR-CRYAA-Mut vector (RiboBio Co., China). HLECs were plated in 24-well plates 
and then transfected with either wild-type or mutant construct with and without miRNA mimic or negative control mimic. Firefly and Renilla luciferase activity was detected $24 \mathrm{~h}$ after transfection using the DualLuciferase Reporter Assay System (Promega, USA).

\section{Western blot}

Western blotting was performed using standard methods. After the specific treatment, wholecell extracts were prepared by RIPA lysis buffer (Beyotime Biotechnology, China) with 1mM Phenylmethanesulfonyl fluoride (PMSF; Beyotime Biotechnology, China). Lysates were centrifuged at $12,000 \mathrm{rpm}$ for $15 \mathrm{~min}$ at $4{ }^{\circ} \mathrm{C}$. Protein concentration of the supernatants was determined using a BCA Protein Assay Kit (Thermo Scientific, USA). Equal amounts $(20 \mu \mathrm{g})$ of the proteins were resolved by $12.5 \%$ SDS-polyacrylamide electrophoresis gels and transferred to nitrocellulose membranes (Millipore, USA). Membranes were blocked in 5\% bovine serum albumin (BSA) for $1 \mathrm{~h}$ at room temperature to reduce nonspecific binding, and then incubated with CRYAA primary antibody $\left(1: 1000 ;\right.$ ab181866, Abcam) at $4{ }^{\circ} \mathrm{C}$ overnight. After washing, the blot was incubated with anti-Rabbit IgG(H+L) secondary antibody (Proteintech, USA) for $1 \mathrm{~h}$ at room temperature. Finally, membranes were scanned using the Odyssey Infrared Imaging System (Odyssey, LI-COR, USA). The representative blot is shown from several experiments.

\section{Statistical analysis}

All data were shown as mean \pm SEM (standard error of the mean), and the experiments were repeated at least three times. Statistical significance was analysed by two-tailed Student's $t$-test or one-way ANOVA followed by post hoc Bonferroni's test using SPSS 16.0 (SPSS Inc., USA). Correlations between H19 and IGF2 expression levels was analysed by Pearson coefficient. $P<0.05$ was considered statistically significant.

\section{Results}

\section{Differential IncRNA expression between transparent and nuclear ARC lenses}

The IncRNA sequencing technique was used to identify nuclear ARC-related lncRNAs. The demographic and clinical features of the study subjects for lncRNA sequencing and qRTPCRs are shown in Table 2. We set the threshold as the fold change $>2.0$, and we identified 63 differentially expressed lncRNAs, including 37 down-regulated lncRNAs and 26 upregulated lncRNAs (nuclear cataractous versus transparent; Table 3). We then conducted hierarchical clustering analysis to obtain an overall comparison of IncRNA expression between the nuclear ARC and the control group. The nuclear ARC samples were clustered together on the same branch, whereas the control samples were clustered on the other branch (Fig. 1A). The scatter plot provided an overall indication of sample reproducibility between different transcripts. The biological replicates displayed similar transcript levels (control sample versus control sample, nuclear ARC sample versus nuclear ARC sample), whereas a significant IncRNA expression difference was detected between the control and the nuclear ARC lens capsules (Fig. 1B). To verify the results of lncRNA sequencing data, we performed qRT-PCRs and found that 9 of 10 lncRNAs were verified to be significantly differentially expressed between nuclear ARC and transparent lens (Fig. 1C). Of them, H19 showed the greatest expression change. This result prompted us to investigate the potential role of lncRNA-H19 in the pathogenesis of nuclear ARC.

LncRNA H19 level is up-regulated in patients with nuclear ARC in a disease developmentdependent manner

H19 has been reported to play important roles in many biological processes, such as cellular differentiation, proliferation and stress tolerance [24, 25].We determined the correlation between H19 expression and nuclear ARC occurrence. The demographic and clinical features of nuclear ARC patients and age-matched controls for qRT-PCR detection are shown in Table 2. The H19 level was significantly up-regulated in all nuclear ARC lens capsules compared with

Table 2. Demographic and clinical features of study subjects for lncRNA sequencing and qRT-PCR verification

\begin{tabular}{lcccc}
\hline Method & Group & Age (y) & LOCUS III grade & Axial length (mm) \\
\hline \multirow{2}{*}{ LncRNA sequencing } & Control & $57.1 \pm 3.8$ & NC 1-2 & $23.47 \pm 0.55$ \\
& ARC & $63.2 \pm 7.0$ & NC 4-6 & $23.54 \pm 0.74$ \\
& Control & $57.4 \pm 3.9$ & NC 1-2 & $23.45 \pm 0.56$ \\
& Grade III & $65.9 \pm 4.7$ & NC 3 & $23.36 \pm 0.78$ \\
qRT-PCR & Grade IV & $68.6 \pm 4.2$ & NC 4 & $23.49 \pm 0.80$ \\
& Grade V & $66.3 \pm 6.1$ & NC 5 & $23.27 \pm 0.97$ \\
& Grade VI & $65.33 \pm 6.2$ & NC 6 & $23.12 \pm 0.83$ \\
\hline
\end{tabular}


the controls (Fig. 2A). We then analysed the correlation between H19 expression and nuclear ARC grade. H19 expression levels were positively associated with nuclear ARC grade $(P<0.01$; Fig. 2B).

The IGF2-H19 locus encodes important paternally imprinted genes that regulate many vital aspects of cell biology via the balance of this 'Yin-Yang' locus [26]. We performed qRT-PCR to detect the IGF2 expression level. In nuclear cataracts, IGF2 was up-regulated in nuclear ARC capsules compared with controls. IGF2 expression was 30.5-fold higher in nuclear ARC compared to transparent lens capsules $(P$ $=0.02$; Fig. 2C). However, no significant correlation between H19 lncRNA and IGF2 mRNA expression levels was detected (Fig. 2D; $r=0.07, P=0.736$ ). This indicated no simple direct co-regulation of both molecules in nuclear ARC lens capsules, suggesting that deregulation by imprinting effects is unlikely.

\section{Effects of H19 knockdown on HLEC} function

To determine whether $\mathrm{H} 19$ regulates primary cultured HLEC function in vitro, $\mathrm{H} 19$ siRNA was transfected into HLECs to downregulate H19 levels (Fig. 3A). Oxidative stress is involved in the pathogenesis of nuclear ARC formation. Oxidative stimulation induced by hydrogen peroxide $\left(\mathrm{H}_{2} \mathrm{O}_{2}, 50 \mu \mathrm{M}\right.$ for $\left.48 \mathrm{~h}\right)$ was performed to observe the effect of H19 knockdown on HLEC viability and apoptosis upon oxidative stress. The MTT assay showed that $\mathrm{H}_{2} \mathrm{O}_{2}(50$ $\mu \mathrm{M}$ ) treatment significantly reduced the viability of HLECs. H19 knockdown further reduced the viability of HLECs (Fig. 3B). Propidium iodide (PI)/Calcein-AM staining indicated that $\mathrm{H}_{2} \mathrm{O}_{2}$ treatment significantly increased the number of dead or dying cells (shown in red). H19 siRNA but not NC siRNA transfection further increased the number of dead or dying cells (Fig. 3C). We also employed Rhodamine 123 and Hoechst double staining to detect the change in mitochondrial membrane potential. Compared with the group only treated with $\mathrm{H}_{2} \mathrm{O}_{2}(50 \mu \mathrm{M}), \mathrm{H} 19$ knockdown further decreased the $\Delta \Psi \mathrm{m}$ (Fig. 3D). The EdU assay revealed that $\mathrm{H}_{2} \mathrm{O}_{2}(50 \mu \mathrm{M})$ treatment significantly decreased the proliferation of HLECs, whereas H19 knockdown further decreased the proliferation (Fig. 3E and Fig. $3 \mathrm{~F}$ ). The transwell assay showed that $\mathrm{H}_{2} \mathrm{O}_{2}$ $(50 \mu \mathrm{M})$ treatment significantly decreased the number of migrated cells. H19 knockdown further decreased the number of migrated cells (Fig. 3G and Fig. 3H). Taken together, these
Table 3. Differentially expressed lncRNAs between transparent and nuclear ARC lens capsules

\begin{tabular}{|c|c|c|}
\hline gene_id & locus & $\begin{array}{c}\log 2 \text { Ratio } \\
\text { (group ARC/group Control) }\end{array}$ \\
\hline n1867 & chr12:97825430-97964194 & -7.24 \\
\hline XLOC_009704|n344497 & chr12:97825430-97964194 & -7.03 \\
\hline n339254 & chr3:13858241-13859396 & -6.41 \\
\hline XLOC_022671|n364709 & chr2:107871146-108200729 & -6.40 \\
\hline n339901 & chr18:59475299-59476953 & -5.87 \\
\hline n407553 & chr16:31579087-31580845 & -5.40 \\
\hline XLOC_037588|n368992 & chr6:19535114-19691245 & -5.13 \\
\hline n345988 & chr15:45119370-45142584 & -4.66 \\
\hline XLOC_042468|64168 & chr8:91803920-91997485 & -4.64 \\
\hline n338841 & chr2:54682158-54898583 & -4.24 \\
\hline n373829 & chr13:112547392-112569826 & -4.24 \\
\hline XLOC_022256|2492 & chr2:49189295-49495815 & -4.21 \\
\hline XLOC_030779|n339559 & chr3:132276981-132593050 & -4.21 \\
\hline n338875 & chr2:70883915-70885457 & -4.20 \\
\hline XLOC_029758|5915 & chr3:25469753-25639423 & -4.15 \\
\hline XLOC_011691|n373699 & chr13:112711196-112764886 & -3.82 \\
\hline n364478 & chr1:213990569-214139608 & -3.80 \\
\hline XLOC_001197|n364204 & chr1:121484052-121485435 & -3.75 \\
\hline n411089 & chr16:5074844-5092972 & -3.63 \\
\hline n635 & chr2:47419543-47572213 & -3.61 \\
\hline n373635 & chr13:112711196-112764886 & -3.53 \\
\hline n384122 & chr22:25844053-25917362 & -3.41 \\
\hline n407558 & chr11:3696239-3847582 & -3.32 \\
\hline n341903 & chr6:72016166-72018653 & -3.21 \\
\hline n381758 & chr11:94883702-94967268 & -3.18 \\
\hline $\mathrm{n} 407051$ & chr9:139607023-139622636 & -3.18 \\
\hline n341102 & chr11:94883702-94967268 & -3.16 \\
\hline n409399 & chr5:95997740-96365115 & -3.11 \\
\hline n410735 & chr12:30862485-30907448 & -3.03 \\
\hline XLOC_009675|n346178 & chr12:93384374-93771512 & -2.63 \\
\hline n332497 & chr4:113739238-114304896 & -2.62 \\
\hline n410447 & chr21:18811099-18822616 & -2.60 \\
\hline XLOC_036485|n369241 & chr6:58776209-58779778 & -2.56 \\
\hline n 407950 & chr21:30671219-30734217 & -2.52 \\
\hline n410546 & chr17:33336130-33448541 & -2.47 \\
\hline n345385 & chr20:31442379-31446532 & -2.30 \\
\hline n334776 & chr16:84599201-84651669 & -2.22 \\
\hline n380292 & chr11:67653916-67673821 & 2.12 \\
\hline n376281 & chr19:29374228-29437336 & 2.14 \\
\hline XLOC_018567|n375742 & chr17:58160923-58169316 & 2.17 \\
\hline n376106 & chr18:6774029-6779022 & 2.20 \\
\hline n384819 & chr6:9708166-10211841 & 2.28 \\
\hline XLOC_035414|n407658 & chr5:134959472-135007336 & 2.49 \\
\hline n373008 & chr12:46773049-47098990 & 2.51 \\
\hline n370562 & chr8:123790128-123792887 & 2.53 \\
\hline n411727 & chr16:21360683-21397254 & 2.61 \\
\hline n381357 & chr1:226722990-226730562 & 2.65 \\
\hline n344593 & chr12:46773049-47098990 & 2.66 \\
\hline XLOC_022187|23498 & chr2:42994228-43024237 & 2.67 \\
\hline n338245 & chr1:153591274-153618782 & 2.95 \\
\hline XLOC_002502|55450 & chr1:20808883-20812728 & 3.02 \\
\hline n376717 & chr20:46417363-46442434 & 3.02 \\
\hline n375838 & chr17:58160923-58169316 & 3.04 \\
\hline XLOC_024818|8708 & chr2:168670688-168727366 & 3.06 \\
\hline n410815 & chr12:58325132-58330391 & 3.08 \\
\hline XLOC_013239|n345747 & chr14:54151725-54360579 & 3.23 \\
\hline n332611 & chr8:41119467-41166990 & 3.38 \\
\hline n377732 & chr19:46684559-46718714 & 3.66 \\
\hline XLOC_021516|n376316 & chr19:46684559-46718714 & 3.70 \\
\hline n346362 & chr14:71288640-71290888 & 3.85 \\
\hline n343066 (H19) & chr11:2016359-2022940 & 4.58 \\
\hline n379688 & chr14:96342728-96413287 & 4.68 \\
\hline XLOC_021515|n377732 & chr19:46684559-46718714 & 5.15 \\
\hline
\end{tabular}


Fig. 1. Differential lncRNA expression between transparent and nuclear ARC lenses samples. (A) Heatmap was generated from the hierarchical cluster analysis to show differentially expressed IncRNAs between control and nuclear ARC lenses capsules. Red indicates down-regulation, and green indicates up-regulation. (B) Scatter plot was used to compare IncRNA expression and nuclear ARC lenses capsules. (C) Nine of 10 IncRNAs were verified by qRT-PCRs to be differentially expressed between nuclear ARC and transparent lens. Log2Ratio change of IncRNA sequencing and fold change of qRT-PCRs were presented. differences between control

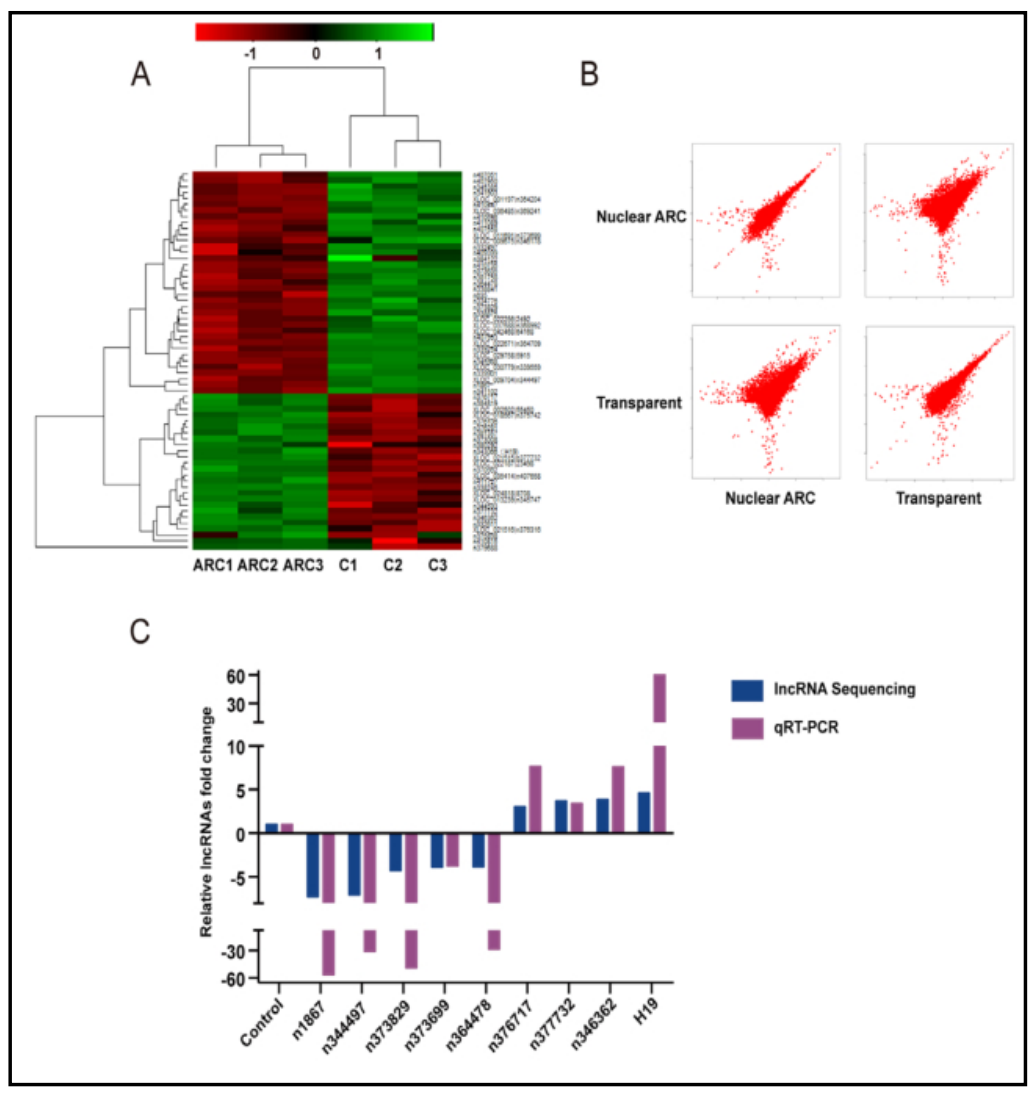

Fig. 2. LncRNA H19 expression levels positively correlate with nuclear ARC grade. (A)qRT-PCRs were performed to detect H19 expression. H19 expression levels were significantly up-regulated in nuclear ARC lens capsules $(n=40)$ compared with controls (n = 10). (B) H19 expression levels were significantly associated with nuclear ARC grade ( $\mathrm{n}=10$ in each control and grade III to VI group). (C) Quantitative RT-PCR on IGF2 in control and ARC lens capsules. Gene expression values are shown as percent
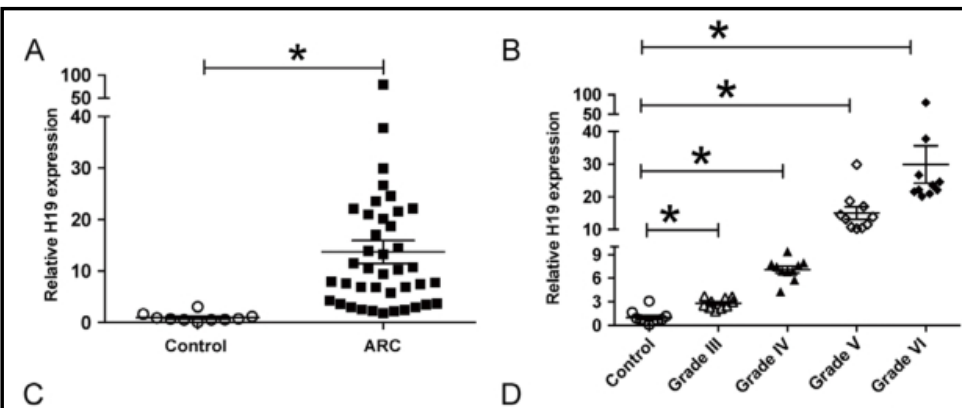

C

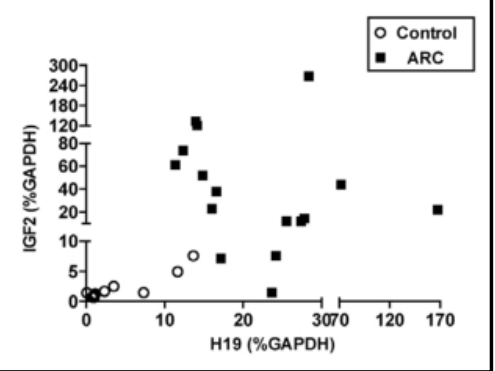
signal normalised to GAPDH.

The data were expressed as relative fold change compared with the control group. ${ }^{*} \mathrm{P}<0.01$. (D) Correlations according to Pearson coefficient between H19 and IGF2 expression levels $(r=0.07, \mathrm{P}=0.736)$.

results show that $\mathrm{H} 19$ regulates the apoptosis, proliferation and migration of primary cultured HLECs under oxidative stress. 
Fig. 3. Effects of H19 knockdown on HLEC function. (A-H) Primary c u l t u r e d HLECs were transfected with H19 siRNA, s c r a m b l e d siRNA (NC) or left untreated. (A) qRT-PCRs were conducted to detected H19 expression levels. ${ }^{*} \mathrm{P}<0.05$. (B-H) After transfection, HLECs were exposed with or without $\mathrm{H}_{2} \mathrm{O}_{2}$ $(50 \mu \mathrm{M})$ for an additional $48 \mathrm{~h}$. (B) Cell viability was detected using the MTT method. $* \mathrm{P}<0.05$.

Apoptotic cells were analysed using $\mathrm{PI}$ and C a l c e in - A M double staining; Green: live cells, Red: dead or dying cell; Scale bar: $50 \mu \mathrm{m}$. (D) Mitochondrial $\mathrm{m}$ e $\mathrm{m}$ b r a n e
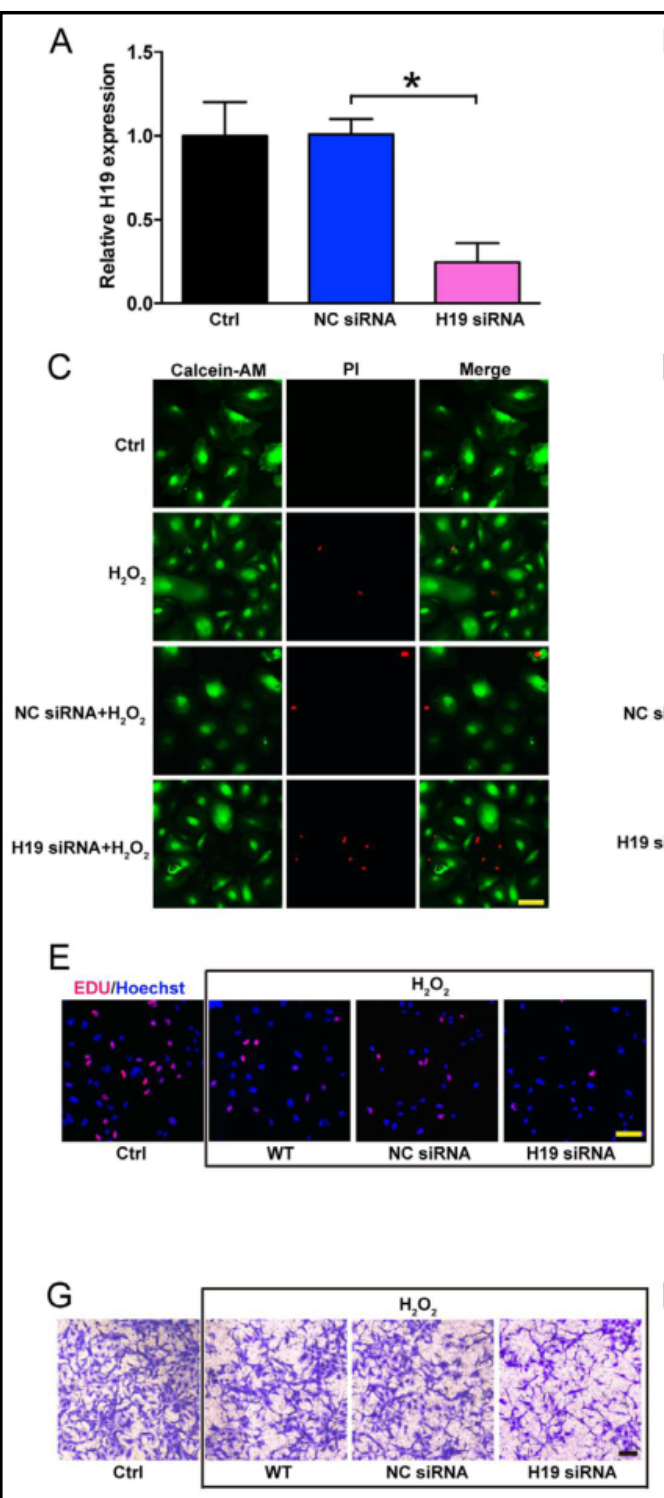
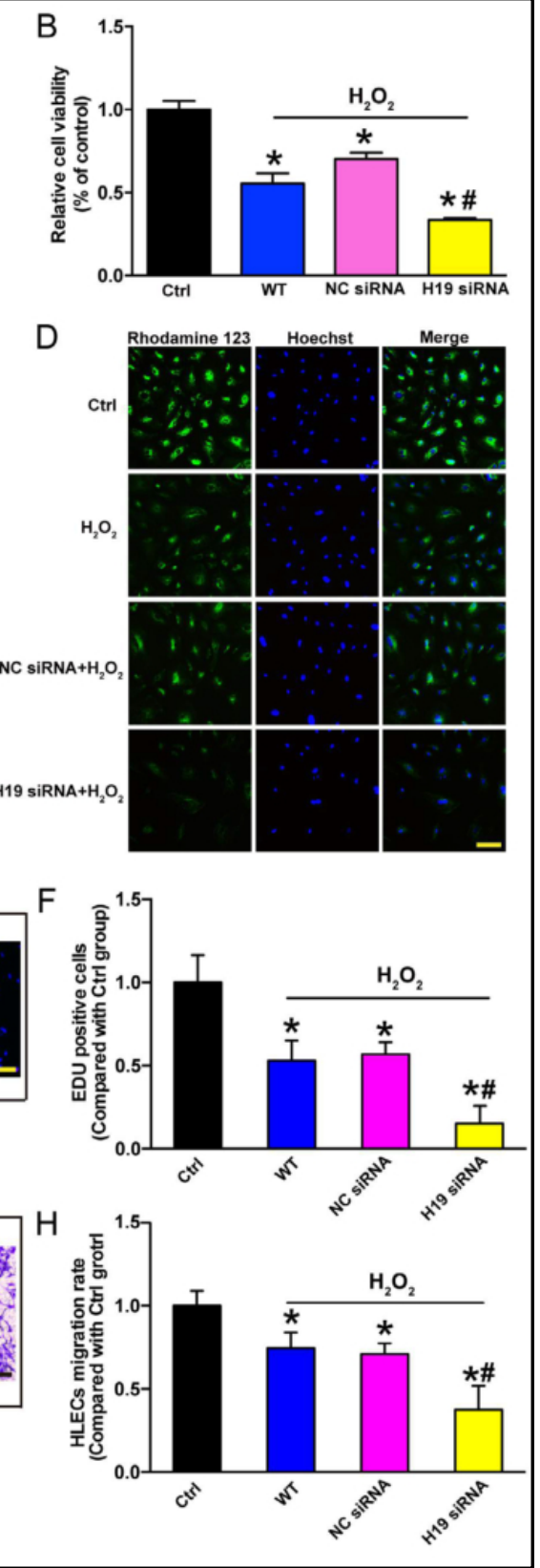

detected using Rhodamine 123 and Hochest 33342 double staining; Scale bar: $20 \mu \mathrm{m}$. (E and F) HLEC proliferation was detected using EdU assay and observed using a fluorescence microscope; Scale bar: $20 \mu \mathrm{m}$. ( $G$ and F) HLEC migration was analysed using transwell assay, Scale bar: $50 \mu \mathrm{m}$. “*” indicates significant difference compared with the control group; "\#” indicates significant difference compared with $\mathrm{H}_{2} \mathrm{O}_{2}$ treatment group, $\mathrm{P}<0.05$.

H19-derived miR675-5p down-regulates the expression of CRYAA

The exon 1 of the H19 gene encodes miR- 675 . We thus investigated the regulatory relationship between miR-675 and H19 expression levels in primary cultured HLECs. The miR-675-5p inhibitor significantly decreased miR-675-5p expression of HLECs, and the miR-675-5p mimic significantly increased it. H19 knockdown significantly decreased miR675 expression compared to NC siRNA. Moreover, miR-675 mimic transfection could rescue the expression level of miR-675 down-regulated by H19 siRNA (Fig. 4A). In silico analysis 
Fig. 4. H19/miR675-5p downregulates the expression of CRYAA. (A) Primary cultured HLECs were transfected with miR-675-5p inhibitor, NC inhibitor, miR-675$5 p$ mimic, NC mimic, H19 siRNA, scrambled siRNA, H19 siRNA + miR675 mimic or left untreated for $48 \mathrm{~h}$. qRT-PCRs were conducted to detected miR-675-5p expression as relative change compared with control group. (B) The wild type and mutant CRYAA 3'-UTR (pmiRCRYAA-WT or pmiR-CRYAA-Mut) were cloned into the downstream of luciferase vector and transfected with miR-675-5p mimic or NC mimic. The luciferase activity was measured by dual-luciferase reporter assay and was normalised to Renilla luciferase activity. (C) Putative binding sites of miR-675 within CRYAA 3'UTR, as predicted by Targetscan website. Algorithms between miR-675 and the 3'UTR of CRYAA and also the mutant CRYAA 3'UTR. (D and E) HLECs were treated as shown. (D) CRYAA levels were detected using qRTPCRs and expressed as relative fold change compared with controls. (E) Western blotting analysis was

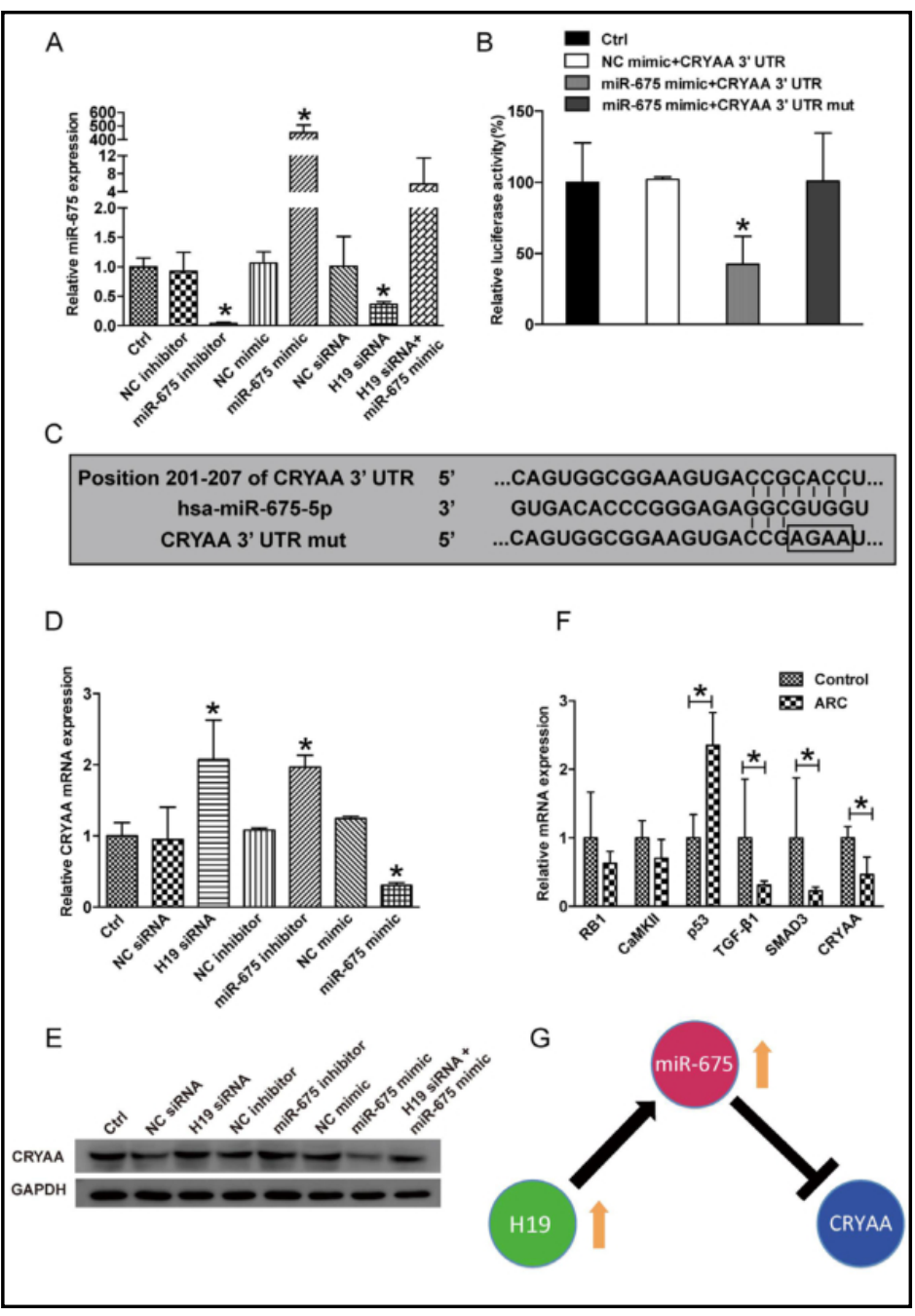
performed to detect the effect of H19 and miR-675 on the protein levels of CRYAA. (F) qRT-PCRs were conducted to detected mRNA expression levels of potential target genes in nuclear ARC capsules as relative change compared with control group. (G) A diagram revealed the potential interaction among H19, miR-675-5p and CRYAA. ${ }^{*} \mathrm{P}<0.05$.

revealed that CRYAA, an important gene encoding the predominant structural proteins involved in the maintenance of lens clarity and refractive properties [24], was a binding target of miR-675 (Fig. 4C). The wild type or mutant 3'-UTR of CRYAA was fused into the luciferase coding region (pmiR-CRYAA-WT or pmiR-CRYAA-Mut) and transfected into HLECs with miR-675-5p mimic or NC mimic. Luciferase reporter assay showed that CRYAA was a target of miR-675-5p (Fig. 4B). Both at the transcriptional and protein level, miR-675-5p inhibitor or H19 siRNA injection significantly up-regulated CRYAA levels in primary cultured HLECs. By contrast, miR-675-5p mimic transfection resulted in a reduction in CRYAA levels (Fig. 4D and Fig. 4E).

Many targets of miR-675 have been identified, such as Twist1 and RB in hepatocellular carcinoma and colorectal cancer [27, 28]; CaMKII $\delta$ in cardiomyocyte hypertrophy [29]; RUNX1 and p53 in bladder cancer [30]; and TGF- $\beta 1 /$ Smad3 in osteogenic differentiation [31]. We thus further investigate the expression level of the above-mentioned target genes between nuclear ARC and transparent lens capsules by qRT-PCR. Twist1 and RUNX1 were undetectable in human lens capsules. No significant differences were found in RB1 and CaMKII $\delta$ expression levels between nuclear ARC and transparent lens capsules. In nuclear 
Fig. 5. miR675$5 \mathrm{p}$ is involved in the regulation of HLEC function. (A-G) HLECs were transfected with miR-675$5 p$ inhibitor, NC inhibitor, miR675-5p mimic, NC mimic, H19 s i R N A + m i R 675-5p mimic or left untreated for $24 \mathrm{~h}$. After transfection, HLECs were exposed with or without $\mathrm{H}_{2} \mathrm{O}_{2}$ $(50 \mu \mathrm{M})$ for an additional $48 \mathrm{~h}$. (A) Cell viability was measured using the MTT method. ${ }^{*} \mathrm{P}<0.05$. (B and C) HLEC proliferation was detected using the EdU assay and observed using a fluorescence microscope ; scale bar: $20 \mu \mathrm{m}$. $* \mathrm{P}<0.05$.

Apoptotic cells were analysed using PI and $\mathrm{C}$ a l c e i n - A M double staining; Green: live cells, Red: dead or dying cell; Scale bar: $50 \mu \mathrm{m}$.(E) Mitochondrial $\mathrm{m}$ e $\mathrm{m} \mathrm{b} \mathrm{r}$ a $\mathrm{e}$ potential was detected using Rhodamine 123 and Hochest 33342 double staining; Scale bar: $20 \mu \mathrm{m}$. (F and G) HLEC migration was analysed using transwell assay, Scale bar: $50 \mu \mathrm{m}$. “*” indicates significant difference compared with the NC inhibitor group; “\#” indicates significant difference compared with the NC mimics group, $\mathrm{P}<0.05$.
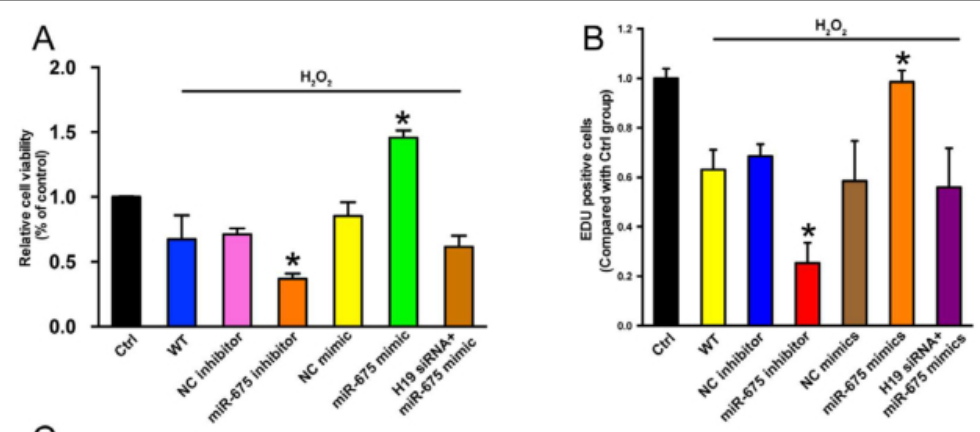

C
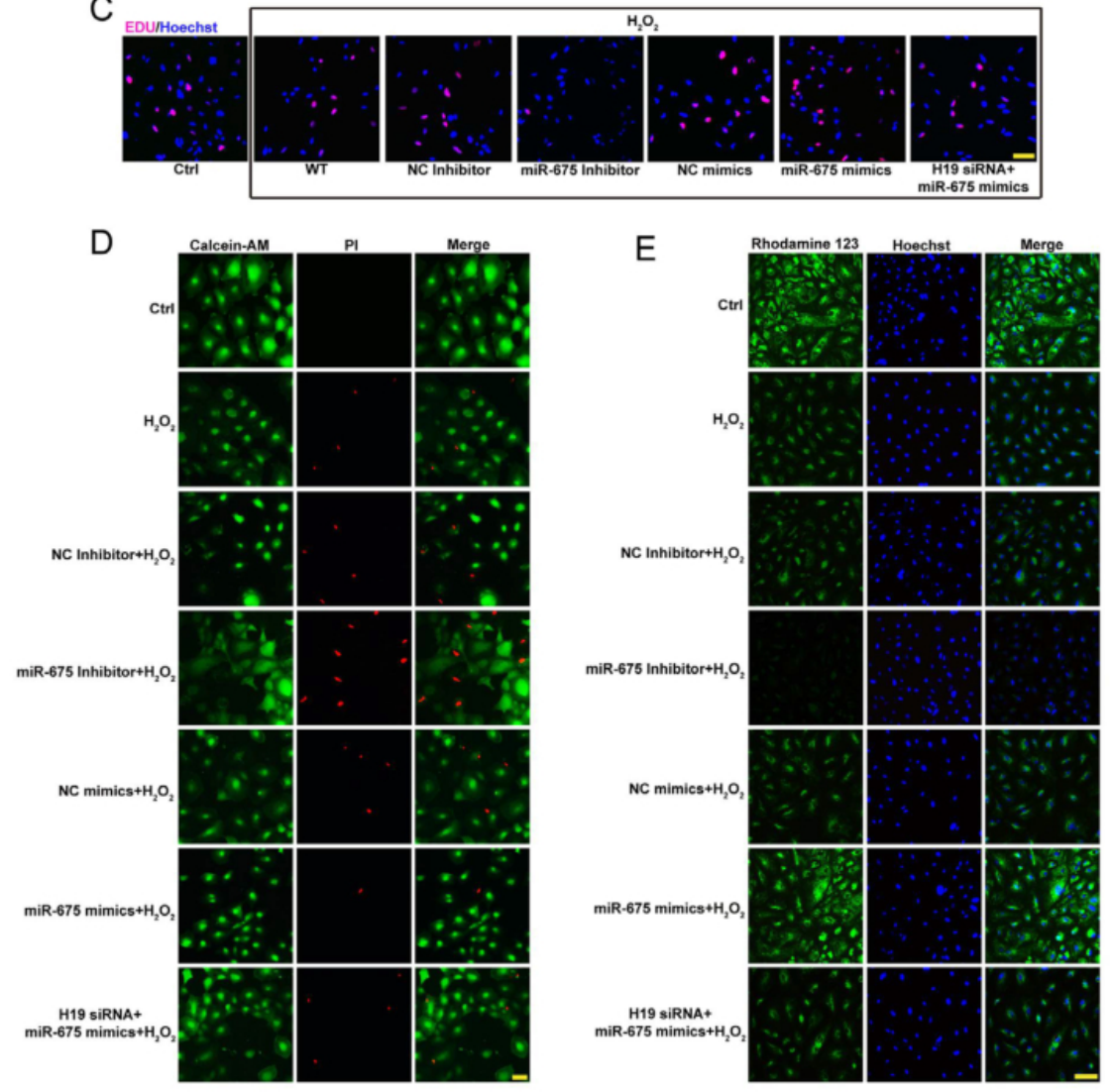

$F$

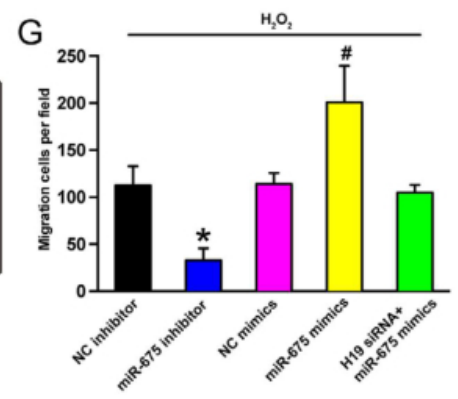


ARC, p53 was up-regulated, and CRYAA, TGF- $\beta 1$ and Smad3 were down-regulated compared to transparent lens capsules (Fig. 4F). Taken together, these results suggest that H19-derived miR-675-5p down-regulates the expression of CRYAA (Fig. 4G).

\section{miR-675-5p is involved in the regulation of HLEC function}

To reveal the role of miR-675-5p in primary cultured HLEC function, HLECs were transfected with miR-675-5p inhibitor or miR-675-5p mimic to regulate miR-675-5p levels. miR-675-5p inhibitor transfection significantly decreased HLEC viability. By contrast, miR675-5p mimic significantly increased the viability (Fig. 5A). miR-675-5p mimic transfection could increase the viability of HLECs affected by H19 siRNA transfection. The EdU assay revealed that miR-675-5p inhibitor transfection could reduce the proliferation of HLECs, whereas miR-675-5p mimic transfection could increase it. miR-675-5p mimic transfection could increase the number of proliferative HLECs affected by H19 siRNA transfection (Fig. 5B and Fig. 5C). miR-675-5p inhibitor transfection could accelerate the development of HLEC apoptosis, whereas miR-675-5p mimic transfection could reduce it. miR-675$5 p$ mimic transfection could decrease the number of apoptotic HLECs affected by H19 siRNA transfection (Fig. 5D). miR-675-5p inhibitor injection could reduce the $\Delta \Psi$ m level, whereas miR-675-5p mimic injection could increase it. miR-675-5p mimic transfection could rescue the $\Delta \Psi$ m level down-regulated by H19 siRNA in HLECs (Fig. 5E). The transwell assay showed that miR-675-5p inhibitor transfection could reduce the number of migrated cells. By contrast, miR-675-5p mimic transfection could increase the number. miR-675-5p mimic transfection could increase the number of migrated HLECs affected by H19 siRNA transfection (Fig. 5F and Fig. 5G). Taken together, these results show that miR-675-5p is involved in the regulation of apoptosis, proliferation and migration of HLECs.

\section{Discussion}

LncRNAs have been reported to be involved in the pathogenesis of several ocular diseases, including corneal neovascularization [32], diabetic retinopathy (DR) $[19,33]$, proliferative vitreoretinopathy (PVR) [34], age-related macular degeneration [35] and cataract [16]. In this study, we used lncRNA sequencing to identify lncRNAs involved in nuclear cataractgenesis. A total of 63 differentially expressed lncRNAs were identified between nuclear ARC and transparent lens capsules. Of them, H19 was verified to be the most significantly up-regulated lncRNA, and its expression was correlated with nuclear ARC grade severity. The H19/miR-675/CRYAA regulatory network is involved in regulating the function of HLECs.

H19, a paternally imprinted gene that encodes a $2.3 \mathrm{~kb} \mathrm{H} 19$ ncRNA, is highly conserved in mammalian development with a very low mutation rate in exons [36]. The IGF2-H19 locus encodes important paternally imprinted genes that regulate embryonic development by the balance of this Yin-Yang locus. Normal somatic imprint is observed in all somatic cells. The proper imprinting of a differentially methylated region (DMR) within this locus, with methylation of the paternal chromosome and a lack of methylation on the maternal chromosome, regulates expression of both of these genes so that Igf2 is transcribed only from the paternal chromosome and $\mathrm{H} 19$ only from the maternal chromosome. Furthermore, erasure of imprinting (hypomethylation) of the Igf2-H19 locus on both chromosomes, which leads to down-regulation of Igf2 and up-regulation of H19 expression, plays an important role in regulating quiescence of pluripotent stem cells in adult organisms and may be involved in the regulation of lifespan. In contrast, hypermethylation of this locus on both chromosomes (loss of imprinting) results in Igf2 overexpression and is observed in several malignancies [26]. Although expression change was observed during cataractgenesis, no erasure or loss of imprinting was found. Therefore, we focus on the downstream pathway of H19 instead of imprinting.

Emerging evidence indicates that $\mathrm{H} 19$ possesses oncogenic, osteogenic differentiatic and cardiopathy genesis properties and is the key regulator in carcinogenesis, metastasis, cell or tissue differentiation and senescence [25, 30, 37, 38]. Overexpression of H19 promotes cellular proliferation, differentiation and migration in vitro, whereas knockdown of H19 inhibits these effects [24, 37, 39]. Down-regulation of H19 also increases apoptosis [24]. We observed similar roles of H19 in HLECs as previously reported in other cells. Oxidative stress 
has long been accepted as an initiating factor in the aetiology of nuclear ARC [40]. Normal function of lenses depends on the balance among oxidative stress, antioxidant protection and repair processes $[15,40]$. Accumulation of reactive oxygen species (ROS) and/or the lack of nuclear glutathione (GSH) could induce apoptosis and lead to the development of nuclear ARC [5, 41]. We show that H19 is up-regulated in nuclear ARC patients compared with controls. Oxidative stress increases the apoptosis of HLECs, whereas H19 knockdown further increases the apoptosis, implying increased H19 levels in nuclear ARC patients is a compensatory response to combat against oxidative stress. However, the compensatory response increases the migration and proliferation of HLECs due to H19 up-regulation. Migration and proliferation of HLECs are closely related to the formation of cataract [42]. Therefore, these side effects, on the other side, promote the formation and progression of cataract.

The mechanism of H19/miR-675-mediated cataractgenesis mainly is explained as shown below. H19, the precursor of miR-675 [24], positively regulates miR-675 expression in nuclear ARC. H19 and miR-675 directly regulate HLEC function in a synergistic way. H19/ miR-675 functions in an indirect way by targeting important downstream genes. Many targets of miR-675 have been identified, such as Twist1 and RB in hepatocellular carcinoma and colorectal cancer [27, 28], CaMKII $\delta$ in cardiomyocyte hypertrophy [29], RUNX1 and p53 in bladder cancer [30], and TGF- $\beta 1 /$ Smad3 in osteogenic differentiation [37]. We show that CRYAA, which encodes the predominant structural protein involved in the maintenance of lens clarity and refractive properties, is a new target of miR-675 in HLECs and is involved in the pathogenesis of nuclear ARC. The H19/miR-675 axis could affect CRYAA expression. The imbalanced expression of $\alpha$-crystallins may accumulate damage and attenuate its protective effect to the lens. Thus, it is not surprising that H19/miR-675 affects the maintenance of lens clarity and refractive properties.

Several studies also report that H19/miR-675 promotes cellular differentiation by negatively regulating several targets in the TGF- $\beta$ signalling pathway $[24,37]$. The TGF- $\beta$ / Smad pathway has also been reported to be a key player involved in pathologic fibrosis of HLECs [43]. When TGF- $\beta$ binds to its receptor, the R-Smad/Smad4 heteromeric complex is formed, transported into the nucleus and combined with a co-repressor or a co-activator to regulate target gene expression [44]. Through this pathway, H19/miR-675 may regulate HLEC function indirectly. Further studies of the H19/miR-675/TGF- $\beta$ regulatory network in the pathogenesis of cataract should be carried out in the future.

Through bioinformatics-based prediction, two deregulated IncRNAs may also be involved in cataractgenesis through different pathways. LncRNA XLOC_009704/n344497, also known as IncRNA RMST, was down-regulated in nuclear ARC compared to transparent lens capsules. RMST is an emerging regulatory lncRNA in epithelial-to-mesenchymal transition (EMT) and cell differentiation $[45,46]$, which may be related to the pathogenesis of cataract $[47,48]$. Previous studies identified a microRNA, miR-135a, whose expression was correlated to the IncRNA RMST. miR-135a was derived from miR-135a-2 locus embedded in RMST $[49,50]$. Functional enrichment analysis with StarBase software identified 17 pathways [51]. Of them, the TGF-beta signalling pathway and IGF1/PIK3/AKT signalling pathway might be correlated to the pathogenesis of ARC $[16,47,52]$. LncRNA XLOC_046118|n371509, which belongs to the IncRNA XIST family, was up-regulated in nuclear ARC compared to transparent lens capsules. Bioinformatics prediction reveals that lncRNA n371509 could act as a let-7 sponge and regulate the let-7 function for binding its target gene. Peng et al. demonstrated that the let-7b microRNA expression was positively associated with patient age and severity of lens opacity [53]. The lncRNA XIST/let-7/TGF- $\beta$ regulatory network might play a role in the pathogenesis of ARC [54-56]. LncRNA-MIAT is shown to be specifically up-regulated both in the plasma fraction of whole blood and aqueous humour of cataract patients. MIAT acts as a ceRNA and forms a feedback loop with Akt and miR-150-5p to regulate HLEC function [16]. The MIAT/miR-150-5p/Akt and H19/miR-675/CRYAA regulatory networks function independently and no crosstalk is found between them. They both are involved in the pathogenesis of ARC and can both affect the function of HLECs. However, further in-depth investigation may clarify the underlying interactions between these two different regulatory networks. They may also regulate HLEC function in a synergistic way. The combined effects would accelerate the development of cataract formation.

The chaperone-like activity of $\alpha$-crystallin (CRYAA) allows the lens to resist aginginduced deterioration of proteins and is considered to be critical for the maintenance of KARGER 
eye lens transparency $[5,9]$. Heredity, senescence and environment are the major factors in CRYAA-related cataractogenesis, and oxidative stress plays an important role as well [5]. We have revealed that CRYAA undergoes epigenetic repression in nuclear ARC [9]. The methylation of the CpG site of the CRYAA promoter directly affects the DNA-binding capacity of transcription factors. DNA-demethylating agent Zebularine treatment up-regulates CRYAA expression in a dose-dependent and time-dependent manner. We here reveal a new pathway involved in the epigenetic repression of CRYAA. Down-regulation of CRYAA via H19/miR675 targeting reduces the expression of chaperones, which is able to bind to the denatured proteins induced by oxidative stress and thus preserve the transparency of the lens [57]. This may accelerate the oxidative modification of proteins in the nucleus, resulting in the pathogenesis of nuclear ARC $[5,12]$.

In summary, we report that 63 lncRNAs are differentially expressed between lens capsules of nuclear ARC and controls. H19 is up-regulated and correlated with ARC grade. H19 could regulate HLECs function through the H19/miR-675/CRYAA regulatory network. This study provides a novel insight into the pathogenesis of nuclear ARC.

\section{Acknowledgements}

We would like to acknowledge Prof. Xu Jianjiang and Dr. Le Qihua, Dr. Li Dan and Dr. Hu Fangyuan, from Eye and ENT Hospital of Fudan University, for their help in clinical sample collection from eye bank and cell culture, respectively. We would like to acknowledge Dr. Zhang Jiwei and Dr. Zhou Menglong, from Fudan University Shanghai Cancer Center, for their help in transwell and dual luciferase assay. We would like to acknowledge Dr. Zhou Xiang, Dr. Hao Qian, Dr. Wang Jieqiong, Dr. Chen Yajie and Dr. Wang Shanshan, from Fudan University Shanghai Cancer Center, for their help in the western blot assay. We would like to acknowledge Prof. Zhou Peng, from Parkway Health Specialty and Inpatient Center, for his help in study design.

This study was supported by grants from the National Natural Science Foundation of China (81371002 and 81870645).

\section{Disclosure Statement}

The authors declare that they have no conflict of interests.

\section{References}

1 Resnikoff S, Pascolini D, Etya’ale D, Kocur I, Pararajasegaram R, Pokharel GP, Mariotti SP: Global data on visual impairment in the year 2002. Bull World Health Organ 2004;82:844-851.

2 Rao GN, Khanna R, Payal A: The global burden of cataract. Curr Opin Ophthalmol 2011;22:4-9.

-3 Carifi G, Miller MH, Pitsas C, Zygoura V, Deshmukh RR, Kopsachilis N, Maurino V: Complications and outcomes of phacoemulsification cataract surgery complicated by anterior capsule tear. Am J Ophthalmol 2015;159:463-469.

4 Chylack LT, Jr., Wolfe JK, Singer DM, Leske MC, Bullimore MA, Bailey IL, Friend J, McCarthy D, Wu SY: The Lens Opacities Classification System III. The Longitudinal Study of Cataract Study Group. Arch Ophthalmol 1993;111:831-836.

5 Michael R, Bron AJ: The ageing lens and cataract: a model of normal and pathological ageing. Philos Trans R Soc Lond B Biol Sci 2011;366:1278-1292.

6 Hammond CJ, Snieder H, Spector TD, Gilbert CE: Genetic and environmental factors in age-related nuclear cataracts in monozygotic and dizygotic twins. N Engl J Med 2000;342:1786-1790.

-7 Heiba IM, Elston RC, Klein BE, Klein R: Genetic etiology of nuclear cataract: evidence for a major gene. Am J Med Genet 1993;47:1208-1214.

8 Liao J, Su X, Chen P, Wang X, Xu L, Li X, Thean L, Tan C, Tan AG, Tay WT, Jun G, Zheng Y, Chew M, Wang YX, Tan QS, Barathi VA, Klein BE, Saw SM, Vithana EN, Tai ES, et al.: Meta-analysis of genome-wide association studies in multiethnic Asians identifies two loci for age-related nuclear cataract. Hum Mol Genet 2014;23:6119-6128. 


\section{Cellular Physiology Cell Physiol Biochem 2018;50:246-260 \begin{tabular}{l|l} 
and Biochemistry Published onlIne: 40ctober 2018 & $\begin{array}{l}\text { C } 2018 \text { The Author(s). Published by S. Karger AG, Basel } \\
\text { www.karger.com/cpb }\end{array}$
\end{tabular}}

-9hou P, Luo Y, Liu X, Fan L, Lu Y: Down-regulation and CpG island hypermethylation of CRYAA in age-related nuclear cataract. FASEB J 2012;26:4897-4902.

$>10$ Zhou P, Lu Y, Sun XH: Zebularine suppresses TGF-beta-induced lens epithelial cell-myofibroblast transdifferentiation by inhibiting MeCP2. Mol Vis 2011;17:2717-2723.

11 Zhou P, Lu Y, Sun XH: Effects of a novel DNA methyltransferase inhibitor Zebularine on human lens epithelial cells. Mol Vis 2012;18:22-28.

-12 Zhu XJ, Zhou P, Zhang KK, Yang J, Luo Y, Lu Y: Epigenetic regulation of alphaA-crystallin in high myopiainduced dark nuclear cataract. PLoS One 2013;8:e81900.

13 Liu X, Zhou P, Fan F, Li D, Wu J, Lu Y, Luo Y: CpG site methylation in CRYAA promoter affect transcription factor Sp1 binding in human lens epithelial cells. BMC Ophthalmol 2016;16:141.

$>14$ Zhu XJ, Zhang KK, Zhou P, Jiang CH, Lu Y: alphaA-crystallin gene CpG islands hypermethylation in nuclear cataract after pars plana vitrectomy. Graefes Arch Clin Exp Ophthalmol 2015;253:1043-1051.

15 Rong X, Qiu X, Jiang Y, Li D, Xu J, Zhang Y, Lu Y: Effects of histone acetylation on superoxide dismutase 1 gene expression in the pathogenesis of senile cataract. Scientific Reports 2016;6:34704.

-16 Shen Y, Dong LF, Zhou RM, Yao J, Song YC, Yang H, Jiang Q Yan B: Role of long non-coding RNA MIAT in proliferation, apoptosis and migration of lens epithelial cells: a clinical and in vitro study. J Cell Mol Med 2016;20:537-548.

17 Jin X, Jin H, Shi Y, Guo Y, Zhang H: Long Non-Coding RNA KCNQ1OT1 Promotes Cataractogenesis via miR214 and Activation of the Caspase-1 Pathway. Cell Physiol Biochem 2017;42:295-305.

18 Yan B, Wang Z: Long noncoding RNA: its physiological and pathological roles. DNA Cell Biol 2012;31:S3441.

19 Yan B, Yao J, Liu JY, Li XM, Wang XQ, Li YJ, Tao ZF, Song YC, Chen Q, Jiang Q: IncRNA-MIAT regulates microvascular dysfunction by functioning as a competing endogenous RNA. Circ Res 2015;116:1143-1156.

20 Yan B, Wang ZH, Guo JT: The research strategies for probing the function of long noncoding RNAs. Genomics 2012;99:76-80.

-21 Wang Z, Gerstein M, Snyder M: RNA-Seq: a revolutionary tool for transcriptomics. Nat Rev Genet 2009;10:57-63.

22 Yan B, Zhao JL: miR-1228 prevents cellular apoptosis through targeting of MOAP1 protein. Apoptosis 2012;17:717-724.

-23 Yan B, Guo JT, Zhu CD, Zhao LH, Zhao JL: miR-203b: a novel regulator of MyoD expression in tilapia skeletal muscle. J Exp Biol 2013;216:447-451.

24 Matouk IJ, Halle D, Raveh E, Gilon M, Sorin V, Hochberg A: The role of the oncofetal H19 lncRNA in tumor metastasis: orchestrating the EMT-MET decision. Oncotarget 2016;7:3748-3765.

-25 Zhou X, Ye F, Yin C, Zhuang Y, Yue G, Zhang G: The Interaction Between MiR-141 and lncRNA-H19 in Regulating Cell Proliferation and Migration in Gastric Cancer. Cell Physiol Biochem 2015;36:1440-1452.

-26 Ratajczak MZ: Igf2-H19, an imprinted tandem gene, is an important regulator of embryonic development, a guardian of proliferation of adult pluripotent stem cells, a regulator of longevity, and a 'passkey' to cancerogenesis. Folia Histochem Cytobiol 2012;50:171-179.

-27 Hernandez JM, Elahi A, Clark CW, Wang J, Humphries LA, Centeno B, Bloom G, Fuchs BC, Yeatman T, Shibata D: miR-675 mediates downregulation of Twist1 and Rb in AFP-secreting hepatocellular carcinoma. Ann Surg Oncol 2013;20:S625-635.

-28 Tsang WP, Ng EK, Ng SS, Jin H, Yu J, Sung JJ, Kwok TT: Oncofetal H19-derived miR-675 regulates tumor suppressor RB in human colorectal cancer. Carcinogenesis 2010;31:350-358.

29 Liu L, An X, Li Z, Song Y, Li L, Zuo S, Liu N, Yang G, Wang H, Cheng X, Zhang Y, Yang X, Wang J: The H19 long noncoding RNA is a novel negative regulator of cardiomyocyte hypertrophy. Cardiovasc Res 2016;111:5665.

-30 Liu C, Chen Z, Fang J, Xu A, Zhang W, Wang Z: H19-derived miR-675 contributes to bladder cancer cell proliferation by regulating p53 activation. Tumour Biol 2016;37:263-270.

31 Huang Y, Zheng Y, Jin C, Li X, Jia L, Li W: Long Non-coding RNA H19 Inhibits Adipocyte Differentiation of Bone Marrow Mesenchymal Stem Cells through Epigenetic Modulation of Histone Deacetylases. Sci Rep 2016;6:28897.

-32 Huang J, Li YJ, Liu JY, Zhang YY, Li XM, Wang LN, Yao J, Jiang Q Yan B: Identification of corneal neovascularization-related long noncoding RNAs through microarray analysis. Cornea 2015;34:580-587.

33 Yan B, Tao ZF, Li XM, Zhang H, Yao J, Jiang Q: Aberrant expression of long noncoding RNAs in early diabetic retinopathy. Invest Ophthalmol Vis Sci 2014;55:941-951.

-34 Zhou RM, Wang XQ Yao J, Shen Y, Chen SN, Yang H, Jiang Q, Yan B: Identification and characterization of proliferative retinopathy-related long noncoding RNAs. Biochem Biophys Res Commun 2015;465:324-330.

-35 Xu XD, Li KR, Li XM, Yao J, Qin J, Yan B: Long non-coding RNAs: new players in ocular neovascularization. Mol Biol Rep 2014;41:4493-4505. 


\section{Cellular Physiology Cell Physiol Biochem 2018;50:246-260 \begin{tabular}{l|l|l} 
and Biochemistry $10.1159 / 000494003$ & $\begin{array}{l}\text { C } 2018 \text { The Author(s). Published by S. Karger AG, Basel } \\
\text { www.karger.com/cpb }\end{array}$
\end{tabular}}

Liu et al.: H19 Regulates HLECs Function

-36 Hurst LD, Smith NG: Molecular evolutionary evidence that H19 mRNA is functional. Trends Genet 1999;15:134-135.

-37 Huang Y, Zheng Y, Jia L, Li W: Long Noncoding RNA H19 Promotes Osteoblast Differentiation Via TGF- $\beta 1 /$ Smad3/HDAC Signaling Pathway by Deriving miR-675. Stem Cells 2015;33:3481-3492.

-38 Cai B, Ma W, Bi C, Yang F, Zhang L, Han Z, Huang Q, Ding F, Li Y, Yan G, Pan Z, Yang B, Lu Y: Long noncoding RNA H19 mediates melatonin inhibition of premature senescence of c-kit(+) cardiac progenitor cells by promoting miR-675. J Pineal Res 2016;61:82-95.

-39 Shi Y, Wang Y, Luan W, Wang P, Tao T, Zhang J, Qian J, Liu N, You Y: Long non-coding RNA H19 promotes glioma cell invasion by deriving miR-675. PLoS One 2014;9:e86295.

40 Varma SD, Chand D, Sharma YR, Kuck JF Jr, Richards RD: Oxidative stress on lens and cataract formation: role of light and oxygen. Curr Eye Res 1984;3:35-57.

-41 Ji Y, Rong X, Li D, Cai L, Rao J, Lu Y: Inhibition of Cartilage Acidic Protein 1 Reduces Ultraviolet B Irradiation Induced-Apoptosis through P38 Mitogen-Activated Protein Kinase and Jun Amino-Terminal Kinase Pathways. Cell Physiol Biochem 2016;39:2275-2286.

42 Su J, Li H: RAC1 overexpression promotes the proliferation, migration and epithelial-mesenchymal transition of lens epithelial cells. Int J Clin Exp Pathol 2015;8:10760-10767.

43 Dawes LJ, Sleeman MA, Anderson IK, Reddan JR, Wormstone IM: TGFbeta/Smad4-dependent and -independent regulation of human lens epithelial cells. Invest Ophthalmol Vis Sci 2009;50:5318-5327.

44 Li J, Tang X, Chen X: Comparative effects of TGF-beta2/Smad2 and TGF-beta2/Smad3 signaling pathways on proliferation, migration, and extracellular matrix production in a human lens cell line. Exp Eye Res 2011;92:173-179.

-45 Yu CY, Kuo HC: The Trans-Spliced Long Noncoding RNA tsRMST Impedes Human Embryonic Stem Cell Differentiation Through WNT5A-Mediated Inhibition of the Epithelial-to-Mesenchymal Transition. Stem Cells 2016;34:2052-2062.

46 Ng S-Y, Bogu Gireesh K, Soh Boon S, Stanton Lawrence W: The Long Noncoding RNA RMST Interacts with SOX2 to Regulate Neurogenesis. Molecular Cell 2013;51:349-359.

47 Du L, Hao M, Li C, Wu W, Wang W, Ma Z, Yang T, Zhang N, Isaac AT, Zhu X, Sun Y, Lu Q, Yin X: Quercetin inhibited epithelial mesenchymal transition in diabetic rats, high-glucose-cultured lens, and SRA01/04 cells through transforming growth factor- $\beta 2$ /phosphoinositide 3-kinase/Akt pathway. Mol Cell Endocrinol 2017;452:44-56.

48 Xiao W, Chen X, Li W, Ye S, Wang W, Luo L, Liu Y: Quantitative analysis of injury-induced anterior subcapsular cataract in the mouse: a model of lens epithelial cells proliferation and epithelialmesenchymal transition. Sci Rep 2015;5:8362.

-49 Caronia-Brown G, Anderegg A, Awatramani R: Expression and functional analysis of the Wnt/beta-catenin induced mir-135a-2 locus in embryonic forebrain development. Neural Dev 2016;11:9.

50 Anderegg A, Lin HP, Chen JA, Caronia-Brown G, Cherepanova N, Yun B, Joksimovic M, Rock J, Harfe BD, Johnson R, Awatramani R: An Lmx1b-miR135a2 regulatory circuit modulates Wnt1/Wnt signaling and determines the size of the midbrain dopaminergic progenitor pool. PLoS Genet 2013;9:e1003973.

51 Cheng Z, Liu F, Zhang H, Li X, Li Y, Li J, Liu F, Cao Y, Cao L, Li F: miR-135a inhibits tumor metastasis and angiogenesis by targeting FAK pathway. Oncotarget 2017;8:31153-31168.

52 Nahomi RB, Pantcheva MB, Nagaraj RH: alphaB-crystallin is essential for the TGF-beta2-mediated epithelial to mesenchymal transition of lens epithelial cells. Biochem J 2016;473:1455-1469.

53 Peng CH, Liu JH, Woung LC, Lin TJ, Chiou SH, Tseng PC, Du WY, Cheng CK, Hu CC, Chien KH, Chen SJ: MicroRNAs and cataracts: correlation among let-7 expression, age and the severity of lens opacity. $\mathrm{Br} \mathrm{J}$ Ophthalmol 2012;96:747-751.

54 Barh D, Malhotra R, Ravi B, Sindhurani P: MicroRNA let-7: an emerging next-generation cancer therapeutic. Curr Oncol 2010;17:70-80.

55 Balzeau J, Menezes MR, Cao S, Hagan JP: The LIN28/let-7 Pathway in Cancer. Front Genet 2017;8:31.

56 Masood N, Yasmin A: Entangling Relation of Micro RNA-let7, miRNA-200 and miRNA-125 with Various Cancers. Pathol Oncol Res 2017;23:707-715.

57 Chen Y, Yi L, Yan GQ Jang YX, Fang YW, Wu XH, Zhou XW, Wei LM: Decreased chaperone activity of alphacrystallins in naphthalene-induced cataract possibly results from C-terminal truncation. J Int Med Res 2010;38:1016-1028. 